\section{Current and Future Uses of Gold in Electronics}

\section{Paul Goodman}

ERA Technology Ltd, Cleeve Road, Leatherhead, Surrey KT22 7SA, UK

E-mail: Paul.Goodman@era.co.uk

\section{Received: 4 February 2002}

The applications for gold in electrical and electronic components are many and varied, and the quantity used is growing steadily especially with the growth in consumer electrical and electronic goods. This paper considers the various applications in the context of the physical and chemical properties of gold relative to other candidate materials. The question of reliability versus cost inevitably enters into the decision to use gold in a particular application, but the use of gold is widespread nevertheless, since it is often cost effective.
Gold has a wide variety of uses in electronics and electrical equipment. Its use has steadily increased during the last 20 years to 280 tonnes in 2000 (1). It has a relatively high price which limits where it is used and equipment manufacturers put in a great deal of effort trying to find lower cost alternatives, not always with success. There are an increasing number of new applications for gold which more than replace those applications where gold has been replaced. Frequently, gold is used at the development stage for a new product and is chosen for its excellent properties and reliability. If the product is manufactured in relatively small numbers, there is little incentive to change but where the scale of production is much larger, lower cost alternatives may sometimes be sought.

\section{How and Where Gold is Used}

Gold is used in electronics mainly in the form of electroplating chemicals, gold bonding wire and sputter targets. Smaller quantities are used in hybrid inks and solders.

The largest use of gold in electronics is as an electroplated coating on connectors and contacts. This is followed by gold bonding wires within semiconductor packages. Other uses include hybrid circuits, solderable coatings for printed circuit boards and components, as gold-based solders and for metal layers on semiconductors as conductor tracks and contact pads.

\section{Connectors and Contacts}

Gold is used on connectors and contacts because it has excellent corrosion resistance, high electrical conductivity (only copper and silver are better) and, alloyed with small amounts of nickel or cobalt, has good wear resistance. For low voltage, low current and low contact force applications, gold is the best material.

The resistivity of metals for electrical contacts is important, but the contact resistance which depends on other factors may be more significant. Some examples are given in Table 1. The contact resistance figures are taken from reference 2 . These figures are very dependent on the test conditions, in particular the contact pressure and so contact resistance data from other sources may not be comparable.

Table 1 Resistivity and Contact Resistance of Some Contact Materials

\begin{tabular}{l|c|c}
\hline Contact Material & $\begin{array}{c}\text { Resistivity } \\
\Omega \mathbf{c m}\end{array}$ & $\begin{array}{c}\text { Contact Resistance } \\
\text { (2) } \mathbf{m} \Omega\end{array}$ \\
\hline Pure gold & $2.4 \times 10^{-8}$ & 0.8 \\
\hline Cobalt hardened gold & $2.4 \times 10^{-8}$ & $2.6-2.8$ \\
\hline Palladium on nickel & $1.08 \times 10^{-7}$ & $3.1-5.8$ \\
\hline Silver & $1.6 \times 10^{-8}$ & Not determined \\
\hline
\end{tabular}


Resistance to oxidation and corrosion is important for connector and contact materials. A useful guide to the susceptibility of metals in these respects is their standard electrode potential although this is not a reliable guide for susceptibility to tarnishing in sulphide atmospheres where silver is particularly liable to attack. The values for a selection of metals are given in Table 2 (3). A large positive value indicates good resistance to corrosion and a large negative value, indicates a high reactivity but the situation is not as simple as this as some metals including aluminium and nickel form very thin, highly protective oxides which prevent further attack once they are formed. However these oxides are usually insulators.

A wide range of materials can be used for connectors and contacts and the most appropriate choice will depend on many criteria which include: current, voltage, contact force, wear, fretting (due to vibration and thermal cycling), environmental conditions (temperature, corrosive gases, etc.) and of course cost (4). The number of times that a connector or contact makes and breaks is also important as it will affect wear. Often a compromise between performance and cost is made. The most commonly used materials for low current and voltage are listed in Table 3 and are compared with gold.

The total area actually making contact in a closed connector or a pair of contacts is usually very small in comparison with the apparent dimensions as contact is made at only a few very small locations. This increases the resistance across the contacts and so the passage of current will generate heat. Increased contact pressure increases the area making contact and so lowers resistance. The voltage and contact pressure both affect localised heating which in turn can lead to surface oxidation (but not of gold) or melting of the surface. Arcing can also occur. All of these will affect the life of the contact (6).

Oxidation or corrosion will affect less noble alloying elements added to gold but these are used to modify its properties such as the hardness or the rate of dissolution in liquid solders. Where a thin gold coating is deposited onto another metal, this will diffuse into the gold and eventually reach the outer surface where it can corrode or oxidise. The time this takes depends on the thickness of the gold layer, the temperature and the nature of the substrate metal. Silver and copper will diffuse faster than nickel and so gold is usually electroplated onto nickel (7). For hostile environments, the gold thickness will need to be increased.

Electrical connectors are used to connect a wide range of equipment such as in computers, mobile phones and cars. Computers have plug-in printed circuit boards with gold plated 'finger' connectors and the various parts of the computer, monitor, printer, etc are connected by plug-in sockets which usually have gold plated pins and sockets. Some examples are shown in Figure 1.

Cars have an increasing number of electrical components which need reliable electrical connections. These include the air bag accelerometers, engine management systems and a variety of pressure and other sensors. Car manufacturers need high reliability and the environment within a car, especially close to the engine, is hostile with a high temperature and so frequently gold is the only suitable material for these conditions. Most other metals would oxidise or corrode. Most connectors are used for very small currents at low voltage and so an increase in contact resistance as a result of oxidation, corrosion or fretting will affect the function of the components.
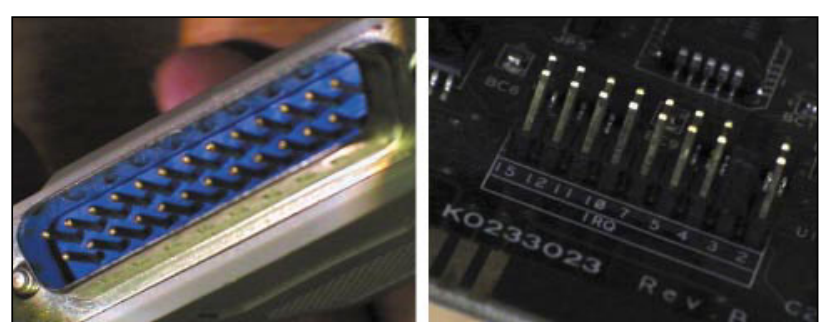

Figure 1

Gold plated computer D plug and connector pins on a computer PCB

Table 2 Standard Electrode Potentials of Metals

\begin{tabular}{lll}
\multicolumn{1}{c}{ Metal } & Standard Electrode Potential (volts) & \multicolumn{1}{c}{ Comments } \\
\hline Gold & $\mathrm{Au}^{+} \rightarrow \mathrm{Au}:+1.68$ & Very inert and resistant to oxidation and corrosion \\
\hline Palladium & $\mathrm{Pd}^{2+} \rightarrow \mathrm{Pd}:+0.83$ & Resistance to corrosion and oxidation less than for gold \\
\hline Silver & $\mathrm{Ag}^{+} \rightarrow \mathrm{Ag}:+0.80$ & $\begin{array}{l}\text { Cood resistance to oxidation and corrosion but susceptible to } \\
\text { sulphide and chloride attack. }\end{array}$ \\
\hline Copper & $\mathrm{Cu}^{2+} \rightarrow \mathrm{Cu}:+0.34$ & Readily oxidises in air and corrodes where moisture is present \\
\hline Tin & $\mathrm{Sn}^{2+} \rightarrow \mathrm{Sn}:-0.136$ & $\begin{array}{l}\text { Forms a thin inert and protective oxide but is easily } \\
\text { damaged because tin is relatively soft }\end{array}$ \\
\hline Nickel & $\mathrm{Ni}^{2+} \rightarrow \mathrm{Ni}:-0.23$ & $\begin{array}{l}\text { Readily forms a thin but inert and highly protective oxide. } \\
\text { This prevents further oxidation but is a good electrical } \\
\text { insulator }\end{array}$ \\
\hline Aluminium & $\begin{array}{l}\text { Aluminium is very reactive but rapidly forms a thin and } \\
\text { inert oxide which is highly protective }\end{array}$ \\
\hline
\end{tabular}


Table 3 Comparison of Connector and Contact Materials

\begin{tabular}{|c|c|}
\hline Coating & MaterialPerformance \\
\hline Gold & $\begin{array}{l}\text { Pure gold is fairly soft so hard gold is usually used. Pure gold is not susceptible to corrosion or } \\
\text { oxidation but alloying elements may be. Hard gold which is alloyed with } 0.4 \% \text { Co cannot be used at } \\
200^{\circ} \mathrm{C} \text { as it forms an insulating oxide whereas gold hardened with nickel is satisfactory at this } \\
\text { temperature (5). Cold is usually electroplated onto nickel. }\end{array}$ \\
\hline Silver & $\begin{array}{l}\text { Often used as substitute for gold due to its lower cost but is susceptible to tarnishing from minute } \\
\text { traces of sulphide. It is fairly soft so wear resistance is not good. }\end{array}$ \\
\hline Tin & $\begin{array}{l}\text { Even cheaper than silver but is very soft, and more susceptible to corrosion. Initial contact resistance } \\
\text { is higher than gold and deteriorates if oxidation or corrosion occurs. Particularly poor where fretting } \\
\text { occurs. }\end{array}$ \\
\hline Palladium/Nickel & $\begin{array}{l}\text { Originally introduced as a lower cost alternative to gold but now palladium is more expensive but is } \\
\text { nevertheless used as it has very good wear resistance. It is however susceptible to oxidation, } \\
\text { corrosion and the formation of insulating films, particularly at higher temperatures. Usually, } \\
\text { palladium is electroplated onto a layer of electroplated nickel. }\end{array}$ \\
\hline Gold/Palladium/Nickel & A thin gold flash is used on palladium to reduce oxidation and corrosion \\
\hline Gold alloys & $\begin{array}{l}\text { Used for electrical contacts and applied by cladding. Dilution of gold reduces costs but the } \\
\text { conductivity is not as high as pure gold. Alloys have good corrosion resistance. }\end{array}$ \\
\hline Copper and its alloys & $\begin{array}{l}\text { Clean unoxidised copper has very good conductivity but oxidation and corrosion can occur rapidly } \\
\text { giving an insulating oxide coating. Useful where higher contact force is available and for power } \\
\text { transmission. }\end{array}$ \\
\hline
\end{tabular}

Internet communication uses high frequency signals to pass data between users. This requires very good and reliable electrical connections and so gold is used for coating connector pins and for sockets in telecommunications generally.

\section{Wire Bonding}

Most semiconductor packages use very fine gold wires to make electrical connections between the semiconductor chip and the leadframe within the package (8). These wires are typically $2 \mathrm{~mm}$ long and $25 \mu \mathrm{m}$ thick so only about 20 nanograms of gold is used per wire. However, some ICs can have over 200 wire bond connections and it is estimated that about 80,000 million ICs were manufactured in 2001 (9), which in total accounts for a large quantity of gold. The quantity of gold used for wire bonding is continually increasing as more and more ICS are manufactured. Gold Fields Mineral Services estimate that demand for gold bonding wire has doubled since 1994 to about 100 tonnes in 2000 and the continuing long term demand for new consumer electronics will ensure that this growth continues (1).

Wire bonding is carried out thermosonically, which uses a combination of heat and ultrasonic energy, or ultrasonically without heat. The use of heat alone is rarely used and is relatively slow. Gold is used for several reasons. Bonding with gold can be carried out thermosonically with very high reliability. This is essential where possibly millions of devices having over 100 leads are manufactured. Manufacturers do not want to carry out complex and costly tests on every device and so rely on being able to achieve a very high yield of good ICs. Another advantage with gold is that ball bonds can be made at a rate of 20 bonds per second. Aluminium is also used for wire bonding (ultrasonically) but reliable ball bonds cannot be made and so wedge bonds have to be used which occupy more space than ball bonds and can be bonded at a rate of only 8 per second. Gold does not oxidise or corrode so packages do not need to be hermetically sealed.

Research into lower cost metals is being carried out. Copper is difficult to use as it forms an inert oxide which prevents bonding. Silver is not used as it does not form good

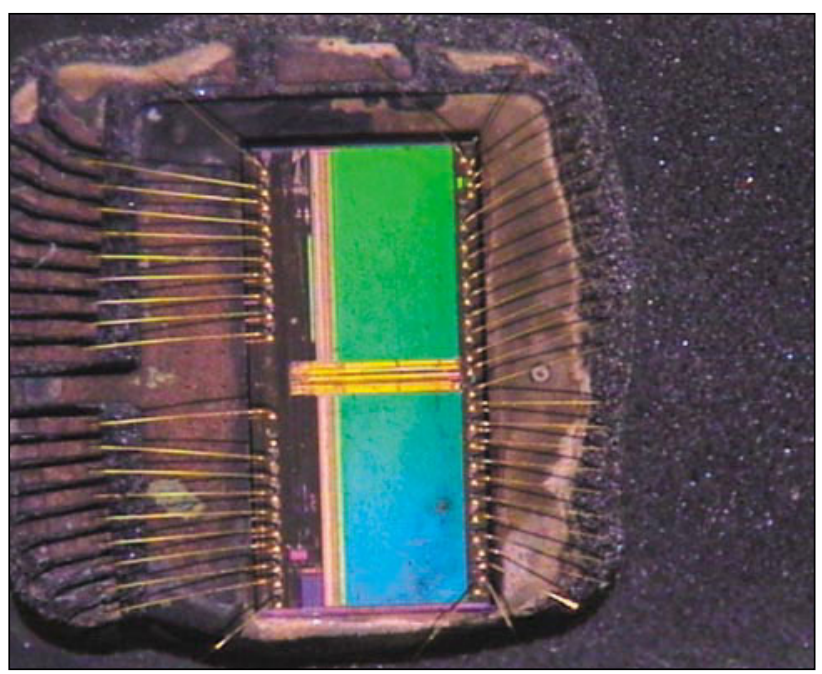

\section{Figure 2}

Plastic packaged IC with the plastic encapsulation removed by acid etching to show gold wire ball bond connections on the chip 
ball bonds, and is susceptible to tarnishing and to electromigration which can lead to short circuiting between electrical connections. The interface between silver wire bonds and the aluminium bonding pads on chips is susceptible to galvanic corrosion, especially under humid conditions. Research into silver/gold alloys is being carried out but reliability is still an issue (10).

\section{Gold Solders}

Silicon chips which produce a significant amount of heat such as those used in power amplifiers need to lose this heat to prevent damage. Generally, any device that produces more than 5 watts needs a good thermally conducting pathway to loose this heat and prevent overheating. This is achieved by bonding the chip to the package using a solder alloy. There are two main choices, tin/lead solders and gold alloys. Eutectic tin/lead forms good bonds and is relatively ductile but is unsuitable if the component leads are soldered with standard solder to a PCB or other parts. High melting point solders having a high lead content can be used but bonds can be porous with voids, which lead to stresses and hotspots in the joint. The properties of the more commonly used die attach solders are listed in Table 4.

The gold solders have better thermal conductivity than tin or lead based solders and they also have higher melting temperatures than the lead-free alloys. Thermal fatigue can also be a problem in power semiconductor components. Gold alloy solders have better fatigue properties than high lead content alloys but of course are more costly. However, a typical IC will use only 2 - 3 mg of gold (11). These gold alloys are the only lead-free solder alternative to high melting point lead-rich solder alloys with melting points in the $280-360^{\circ} \mathrm{C}$ range.

Gold tin solder is also used to hermetically seal some types of packaging. One example is laser diodes used for internet communications using 80Au20Sn for the package lid seal as well as the die attach solder.

Table 4 Die Attach Solder Properties

\begin{tabular}{l|c|c}
\hline Alloy & $\begin{array}{c}\text { Thermal Conductivity } \\
\text { W/mK }\end{array}$ & $\begin{array}{c}\text { Melting } \\
\text { Temperature }{ }^{\circ} \mathbf{C}\end{array}$ \\
\hline 63\%Sn37\%Pb & 51 & 183 \\
\hline 99Sn1Sb & 29 & 235 \\
\hline 88\%Pb10\%Sn2\%Ag & 27 & $268-290$ \\
\hline 90\%Pb5\%Sn5\%Ag & 26 & 292 \\
\hline Gold Tin & 57 & 280 \\
\hline Gold Silicon & 27 & 363 \\
\hline Gold Germanium & 44 & 361 \\
\hline
\end{tabular}

\section{Solderable Coatings}

Gold is wetted very easily by liquid solders and so is used as a protective solderable coating. Once a printed circuit board (PCB) has been manufactured, the copper circuitry rapidly oxidises and it soon becomes impossible for solder to wet the surface using an electronics flux. Therefore PCB manufacturers nearly always coat their boards with a protective coating to protect them during storage. One of the most popular is electroless nickel, followed by immersion gold (12). This is more costly than some of the alternatives but gives superior performance. Organic solderability preservatives (OSP) are popular because they are low cost but the protective coating is very susceptible to damage by fingerprints and light rubbing. Tin and silver coatings are also available and are less susceptible to damage than OSPs but more susceptible to tarnishing or corrosion than nickel/gold.

Nickel gold forms a very flat surface and is suitable for soldering bare chips directly onto the PCB. Another advantage is that the gold colour makes inspection easier, but rework can be more difficult. The thickness of gold used is typically $0.08 \mu \mathrm{m}$ so very little gold is used on each PCB. When soldered, this very small quantity of gold dissolves into the solder and remains in solution so does not affect joint reliability. The solder forms a strong bond to the nickel which dissolves much more slowly in liquid solder than gold or copper. Nickel cannot be used alone without the thin immersion gold layer as it oxidises on exposure to air to form a thin layer of a very stable oxide which prevents solder wetting the surface. Extremely corrosive fluxes, which would alleviate this problem, are unsuitable for electronic circuits.

Electromigration is a process that can affect printed circuit boards, hybrid PCBs and some electronic components under certain conditions such as high humidity, an electrical potential and ionic material, such as flux residues (13). Silver is particularly prone to electromigration but most other metals will also do this under certain conditions. Even aluminium conductors within semiconductor integrated circuits have been known to suffer from electromigration. Electromigration of gold is very rare and occurs only if chloride ions are present. Electromigration appears as a filamental growth of metal that runs between two conductors and is an electrochemical process. Metal from the anode dissolves and diffuses under the influence of an applied current and is electroplated onto the negative electrode.

Anode reaction - metal dissolution with release of electrons:

$$
M=M^{n+}+n e^{-}
$$

Cathode reaction - metal electroplating, consumes electrons:

$$
M^{n+}+n e^{-}=M
$$


The relatively large positive electrode potential of gold makes these reactions less likely to occur than with other more reactive metals.

\section{Hybrid Circuits}

Where the higher production cost is justified, hybrid circuits are used as they have many advantages over plastic laminate PCBs. Hybrids are normally used to save space and weight but thermal dissipation is better. Signal paths are shorter so that circuits are faster, they can use less power and they have enhanced performance at high frequencies, and are therefore often used for microwave circuits. It is possible to build resistors, capacitors and inductors into inner layers which saves space on the outer layers. Some types can be made with hundreds of individual layers and circuits can safely be used at over $100^{\circ} \mathrm{C}$, neither of which is possible for standard FR4 PCBs.

Hybrid circuits use metal inks to create the conductors. Gold, silver, palladium, platinum and their alloys are used as circuits and need to be fired at $850^{\circ} \mathrm{C}$ during manufacture. The inks or pastes contain metals in the form of fine powders. As a conductor, gold is the best material as it has high conductivity and excellent resistance to corrosion. However it is more expensive than silver which is an even better conductor but can suffer from tarnishing and electromigration problems. Despite these potential difficulties, many hundreds of times as much silver is used as gold. Gold is, however, usually used for wire bond pads. A hybrid circuit can be overall a lower cost option than a plastic laminate board. Bosch have developed an ABS module which is designed to be fitted close to the engine. This avoids the need for an expensive cable so that the overall cost is lower.

One of the advantages with hybrid circuits is that a very fine pitch can be achieved although the limit is currently about 400 $\mu \mathrm{m}$ (line + space) for screen printed circuitry. There

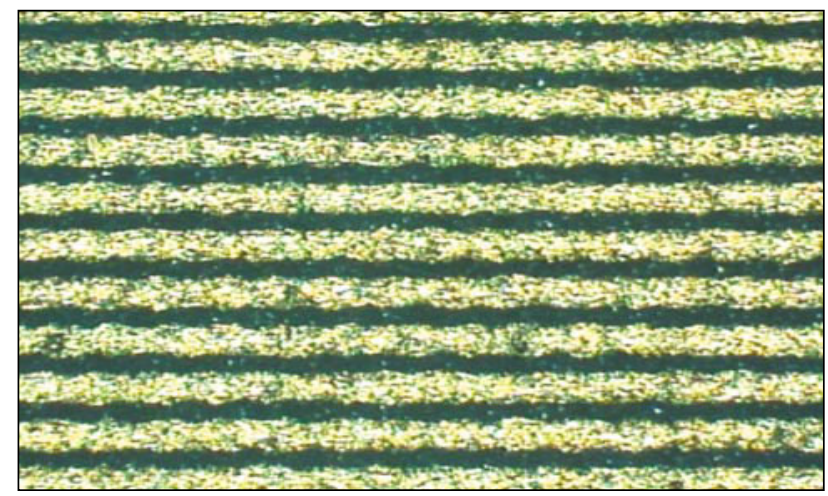

Figure 3

50um gold lines and spaces printed onto an alumina substrate using an ERA $\mu$-Screen are new products on the market from Dupont and from Heraeus for making finer lines using photolithographic techniques but these involve several process steps and create effluents and are therefore relatively expensive. An alternative is to print directly with the ERA $\mu$-Screen $(14,15)$.

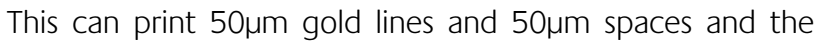
edges of lines are much smoother than screen printed lines which are affected by the weave of the mesh screens. This gives superior performance with high frequency circuits.

\section{Sputter Coated Gold}

Gold can be coated onto a wide variety of substrates including metals, ceramics and plastics using various vacuum coating techniques. With sputtering, gold is used in the form of a 'target' which is a specially shaped piece of gold. High energy ions eject atoms of gold from the surface and these are deposited onto the material which is being coated. The quantity of gold that is sputtered has increased significantly over the last few years, mainly due to the introduction of Read/Write CDs and DVDs. These have a very thin pure gold coating that is deposited by sputtering. Gold is used because it is the best optical reflector with excellent resistance to corrosion and tarnishing.

Gold is also sputter coated onto gallium arsenide (GaAs) integrated circuits as the conducting pathways. Gold is not used on silicon as it reacts with the silicon (for which aluminium and more recently copper conductors are used) but it can be used on GaAs and other compound semiconductors unlike aluminium which interacts (16). The use of GaAs ICs has increased significantly recently as a result of new uses in mobile phones, internet communications and DVD players. GaAs is used because signal speeds are up to 40 times faster than with silicon.

There is a rapid growth in the use of microelectromechanical systems (MEMS) devices for a wide range of applications (17). These include crash sensors in automobiles, optical switches for the internet and pressure sensors for automobiles and medical applications. Their use in mobile phones is predicted to grow rapidly as MEMS switches and other devices are introduced. Most optical switches are coated with a thin layer of gold, using a vacuum technique, to make a reflecting mirror surface. Most MEMS switches operate with a very low contact force and so only gold can be used to obtain a low contact resistance.

\section{Recycling of Gold from Electronics}

The EU is planning to introduce the Waste from Electrical and Electronic Equipment (WEEE) directive which will require 
manufacturers to recycle electronic and electrical equipment at the 'end of life'. Currently, only equipment that can be recycled economically is recycled and the most valuable component in often gold, particularly in IT and telecom scrap. The final form of the directive is still unclear but manufacturers will have to pay for their products to be recycled and any recovered gold will contribute to cost savings (18).

\section{Conclusions}

Gold has a wide variety of uses in electronics because of its unique physical and chemical properties:

- It has excellent resistance to corrosion and oxidation, whereas silver tarnishes in atmospheres containing minute traces of sulphide. Palladium oxidises especially at higher temperatures and can catalyse the polymerisation of hydrocarbons and form insulating films. Most other metals including copper, nickel, iron and cobalt will oxidise in air and corrode in the presence of moisture and ions, particularly halides.

- The inertness of gold makes it invaluable as a solderable coating to maintain the solder wetting properties of PCBs and component leads. It also allows gold to be used within the human body as it is not affected by body fluids and is completely non-toxic.

- The electrical resistivity of gold is the lowest of all metals except for silver and copper but both of these readily tarnish causing the contact resistance to increase. For low current, low voltage conditions and low contact force, gold is frequently the best choice technically and in some applications such as automotive and RF connectors and MEMS switch contacts, it is the only choice.

- Pure gold is a relatively soft metal and so is not ideal for contacts where wear occurs. Hard gold has been developed for wear applications but better results are obtained if this is electroplated onto Pd/Ni layers.

- Gold's ductile properties combined with the lack of an air formed oxide allows fine gold wires to be used for wire bonding within semiconductor ICs. No other metal has the same reliability at the highest production rates.

- Cold is also used for its light reflecting properties in optical devices such as optical switches and Read/Write CDs and DVDs.

The only significant disadvantage of gold that sometimes discourages its more widespread use is relatively high metal price compared with base metals such as copper and nickel. Usually, however, only very small quantities of gold are used in each product so the effect on the total cost is often insignificant whereas improved reliability can result in significant savings.

\section{About the Author}

Dr Paul Goodman gained his first degree in chemistry at Nottingham University in 1976 and his PhD at Warwick University in 1980. He worked for the Cookson Group for 14 years on a variety of materials and processes related to electronics, including solder pastes, novel fluxes, PCB manufacture, flame retardants and indium based materials.

He has worked for ERA Technology since 2000 where he is involved in several areas including the Reliability and Failure Analysis Service which identifies the causes of failures to electrical equipment and components and recommends solutions. He has also optimised a production process for a novel silicon MEMS sensor and co-authored several ERA publications on topics in electronics including soldering, hazardous materials in electronics and MEMS.

\section{References}

1 Gold Survey 2001, Gold Fields Mineral Services Ltd, April 2001

2 P.W. Lees, Proceedings of the Technical Program, NEPCON, June 1996

3 Handbook of Chemistry and Physics, 53rd Edition, ed. R. C. Weast, CRC Press 1972

4 Y.Okinaka and T. Homma, Proc. Electrochem. Soc. International Symposium, 2000, 99 (34), 132

5 H. Kumakura and M. Sekiguchi, IEICE Transactions on Electronics, 1999, E82-C(1), 13

6 D. Charman , C. Turner and H. W. Turner ERA Technology Ltd Report 90-0405R, 1990

7 E. D. Winters, J. M. Coronati, D. N. Braski and T. R. Watkins, Plating and Surface Finishing, 2000, 87 (3), 68 - 70, 72 - 75

8 Ch. Simons, L. Schrapler and G. Herklotz, Gold Bull., 2000, 33(3), 89 96 and 102

9 Chipscale Review website at http://chipscalereview.com/ issues/0501/trends.html

10 US Patent 6150262, Texas Instruments, 2000

11 Data from Philips Semiconductors website at www.semiconductors.philips.com

12 I. Young, Printed Circuit Fabrication, 1998, 21(9), 38, 40, 42, 44, 46 - 49

13 R. C. Benson, B. M. Romenesko, J. A. Weiner, B. N. Hall and H. K. Charles, IEEE Trans. Components, Hybrids and Manufacturing Technology, 1988, 11(4), 363

14 ERA $\mu$-Screen. http://www.era.co.uk/microscreen.htm

15 B. Walton and G.P. Shorthouse, GB Patent 2,201,637, 1990

16 C. I. Wu, A. Kahn, A. E. Wickendon, D. Koleske and R. L. Henry, J. Appl. Physics, 2001, 89(1), 425

17 Market Analysis for Microsystems 1996 - 2002, The Network of Excellence in Multifunctional Microsystems. (www.nexus-emsto.com)

18 R. Holliday, C. Corti and P. Goodman, Proceedings of Recycling Electrical and Electronic Equipment, London, November 2001, p. 18-1 